University of Nebraska - Lincoln

DigitalCommons@University of Nebraska - Lincoln

USDA National Wildlife Research Center - Staff Publications
U.S. Department of Agriculture: Animal and Plant Health Inspection Service

2020

\title{
Validation of a screening method for the detection of colistin- resistant $E$. coli containing mcr-1 in feral swine feces
}

Jeffrey C. Chandler

NWRC APHIS USDA, jeffrey.c.chandler@usda.gov

Alan B. Franklin

USDA-APHIS-WS National Wildlife Research Center, alan.b.franklin@aphis.usda.gov

S. N. Bevins

US Department of Agriculture-National Wildlife Research Center, Sarah.N.Bevins@aphis.usda.gov

Kevin T. Bentler

National Wildlife Research Center, kevin.t.bentler@aphis.usda.gov

Jonas Bonnedahl

Linköping University, Sweden, jonas.bonnedahl@liu.se

Follow this and additional works at: https://digitalcommons.unl.edu/icwdm_usdanwrc

Part of the Natural Resources and Conservation Commons, Natural Resources Management and

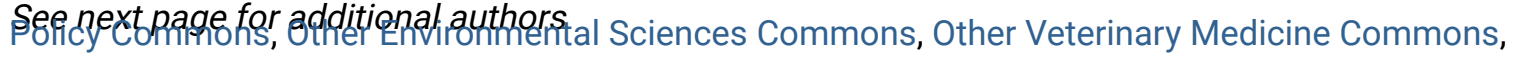
Population Biology Commons, Terrestrial and Aquatic Ecology Commons, Veterinary Infectious Diseases Commons, Veterinary Microbiology and Immunobiology Commons, Veterinary Preventive Medicine, Epidemiology, and Public Health Commons, and the Zoology Commons

Chandler, Jeffrey C.; Franklin, Alan B.; Bevins, S. N.; Bentler, Kevin T.; Bonnedahl, Jonas; Ahlstrom, Christina A.; Bisha, Bledar; and Shriner, Susan A., "Validation of a screening method for the detection of colistinresistant E. coli containing mcr-1 in feral swine feces" (2020). USDA National Wildlife Research Center Staff Publications. 2338.

https://digitalcommons.unl.edu/icwdm_usdanwrc/2338

This Article is brought to you for free and open access by the U.S. Department of Agriculture: Animal and Plant Health Inspection Service at DigitalCommons@University of Nebraska - Lincoln. It has been accepted for inclusion in USDA National Wildlife Research Center - Staff Publications by an authorized administrator of DigitalCommons@University of Nebraska - Lincoln. 


\section{Authors}

Jeffrey C. Chandler, Alan B. Franklin, S. N. Bevins, Kevin T. Bentler, Jonas Bonnedahl, Christina A. Ahlstrom, Bledar Bisha, and Susan A. Shriner 


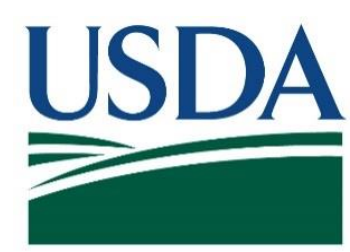

U.S. Department of Agriculture

U.S. Government Publication

Animal and Plant Health Inspection Service

Wildlife Services 


\title{
Validation of a screening method for the detection of colistin-resistant $E$. coli containing $m c r-1$ in feral swine feces
}

\author{
Jeffrey C. Chandler ${ }^{\mathrm{a}, *}$, Alan B. Franklin ${ }^{\mathrm{a}}$, Sarah N. Bevins ${ }^{\mathrm{a}}$, Kevin T. Bentler ${ }^{\mathrm{a}}$, Jonas Bonnedahl ${ }^{\mathrm{b}}$, \\ Christina A. Ahlstrom ${ }^{\mathrm{c}}$, Bledar Bisha ${ }^{\mathrm{d}}$, Susan A. Shriner ${ }^{\mathrm{a}}$
}

${ }^{a}$ U.S. Department of Agriculture, National Wildlife Research Center, Fort Collins, CO, USA

${ }^{\mathrm{b}}$ Research section, Region Kalmar County, The Department of Biomedical and Clinical Sciences, Linköping University, Sweden

${ }^{\mathrm{c}}$ U.S. Geological Survey, Alaska Science Center, Anchorage, AK, USA

${ }^{\mathrm{d}}$ Department of Animal Science, University of Wyoming, Laramie, WY, USA

\section{A B S T R A C T}

A method was developed and validated for the detection of colistin-resistant Escherichia coli containing mcr-1 in the feces of feral swine. Following optimization of an enrichment method using EC broth supplemented with colistin $(1 \mu \mathrm{g} / \mathrm{mL})$ and vancomycin $(8 \mu \mathrm{g} / \mathrm{mL})$, aliquots derived from 100 feral swine fecal samples were spiked with of one of five different mcr-1 positive E. coli strains (between $10^{\circ}$ and $10^{4} \mathrm{CFU} / \mathrm{g}$ ), for a total of 1110 samples tested. Enrichments were then screened using a simple boil-prep and a previously developed real-time PCR assay for $\mathrm{mcr}-1$ detection. The sensitivity of the method was determined in swine feces, with $\mathrm{mcr}-1$ E. coli inocula of $0.1-9.99 \mathrm{CFU} / \mathrm{g}(n=340), 10-49.99 \mathrm{CFU} / \mathrm{g}(n=170), 50-99 \mathrm{CFU} / \mathrm{g}(n=255), 100-149 \mathrm{CFU} / \mathrm{g}(n=60)$, and $200-2200 \mathrm{CFU} / \mathrm{g}(n=175)$, which were detected with $32 \%, 72 \%, 88 \%, 95 \%$, and $98 \%$ accuracy, respectively. Uninoculated controls $(n=100)$ were negative for $m c r-1$ following enrichment.

\section{Introduction}

The antibiotic colistin has been used for growth promotion in livestock since the 1960s (Apostolakos and Piccirillo, 2018; Rhouma et al., 2016). Coincident with colistin use in animal agriculture was an apparent increase in colistin resistance in the microbial communities associated with these systems (Apostolakos and Piccirillo, 2018). This is problematic given that colistin is considered as a drug of last resort for the treatment of extensively drug-resistant and carbapenem-resistant bacterial infections in humans (Biswas et al., 2012; Lim et al., 2010; Watkins et al., 2016). Historically, colistin resistance was considered to be mediated by point mutations of chromosomally-encoded genes (Liu et al., 2016). However, in 2015, a plasmid-encoded colistin resistance gene, mobilized colistin resistance gene 1 ( $m c r-1)$, was described in China (Liu et al., 2016). It is accepted that $m c r-1$ is exchanged between bacteria through horizontal gene transfer, increasing the likelihood of colistin resistance being acquired by human and veterinary pathogens. Nine $\mathrm{mcr}$ homologs ( $\mathrm{mcr}-1$ to $\mathrm{mcr}$-9, note $\mathrm{mcr}$ - 2 may be considered as a variant of $m c r-1$ ) have currently been described, with multiple variants and types of $\mathrm{mcr}$ genes detected in the United States (U.S.) (Carroll et al., 2019; Wang et al., 2018; Xavier et al., 2016). Further, molecular epidemiological analyses suggest that some Chinese mcr-1 positive bacterial isolates found in association with human disease can be linked to animal agriculture (Wang et al., 2017).
Livestock production systems have multiple pathways that allow for the introduction and dissemination of microorganisms. Among these pathways, wildlife can directly interact with livestock, serve as reservoirs of antimicrobial resistant bacteria and genes, serve as hosts for the development and exchange of the genetic determinants of antibiotic resistance, and act as mechanical vectors for disseminating antimicrobial resistant bacteria into the food chain and across the landscape (Greig et al., 2015; Radhouani et al., 2014). Globally, bacteria encoding $\mathrm{mcr}$ have been found within the gastrointestinal tracts of wildlife, suggesting that wildlife could have an important role in the development and dissemination of colistin resistance through fecalmediated contamination (Bachiri et al., 2018; Carroll et al., 2019; Liakopoulos et al., 2016; Ruzauskas and Vaskeviciute, 2016). Of particular concern are feral swine, given their expanding population and geographic distribution globally (Bevins et al., 2014; Snow et al., 2017) and the association of $m c r-1$ with domestic swine in China (Liu et al., 2016). In addition to the extensive ecological and agriculture damage they cause, feral swine interactions with livestock and people may potentiate the spread of infectious disease (Bevins et al., 2014). Recently, $m c r-9$ was detected in an Escherichia coli isolate from a wild boar in South Dakota (NCBI BioSample SAMN04902855), and was also identified in Salmonella enterica isolates collected from domestic swine in Minnesota and Texas (Carroll et al., 2019). Similarly, mcr-1 E.coli was found in association with domestic swine in 2016 in Illinois and South

\footnotetext{
* Corresponding author at: U.S. Department of Agriculture, National Wildlife Research Center, Fort Collins, CO, USA.

E-mail address: jeffrey.c.chandler@usda.gov (J.C. Chandler).
} 
Carolina (NCBI BioSamples SAMN05346848 and SAMN05177221) (Meinersmann et al., 2017). Numerous other studies suggest that swine are an important reservoir of $\mathrm{mcr}$ throughout the world (Alba et al., 2018; Clemente et al., 2019; Yang et al., 2019). These data suggest that both domestic and feral swine could contribute to the maintenance and dissemination of $m c r$-containing bacteria in the U.S.

$E$. coli are recognized as a main host of $m c r-1$, and these bacteria are found in humans, animals, and the environment making them ideal indicator organisms for $m c r-1$ monitoring and surveillance (Fernandes et al., 2017). While methods for the screening of colistin-resistant $E$. coli have been reported, methods to detect colistin resistance in swine may have sub-optimal sensitivity (Mourand et al., 2018; Osei Sekyere, 2019), and no method has been specifically optimized or validated for the screening of feral swine feces for $E$. coli containing $m c r-1$. Therefore, the objective of this study was to develop and validate a method for detecting mcr-1 E. coli in the feces of feral swine. This procedure coupled selective enrichment with real-time PCR-based detection of $\mathrm{mcr}-1$. The method was designed to be simple and cost-effective, limiting the need for multi-step enrichments and extensive nucleic acid preparation steps, to facilitate national-level monitoring of this target. The optimized method was validated using feral swine fecal samples spiked with various concentrations of one of five $m c r-1 \mathrm{E}$. coli strains of wildlife origin.

\section{Methods}

\subsection{Bacteria}

E. coli strains SP 237, M 175, SP 167, POR 1303, and SP 278 containing mcr-1 were collected from wild birds (Larus spp.) and genetically characterized in previous studies (Ahlstrom et al., 2019). These bacteria were maintained as glycerol stocks and stored at $-80{ }^{\circ} \mathrm{C}$ until use. To prepare the inocula for fecal spikes, approximately $1 \mu \mathrm{L}$ of the glycerol stock was added to $10 \mathrm{~mL}$ of tryptic soy broth (Becton Dickinson, Franklin Lakes, NJ, U.S.) and incubated statically for 18-24 h at $37^{\circ} \mathrm{C}$. The bacterial concentrations of inocula were then determined by surface plating using CHROMAgar COL-APSE (CHROMagar, Paris, FRA) in accordance with the manufacturer's instructions.

\subsection{Swine fecal samples}

Feral swine fecal samples were opportunistically collected in Alabama, U.S., from May to July 2019 as part of ongoing studies supported by the U.S. Department of Agriculture's National Feral Swine Damage Management Program. Upon collection, the samples were immediately placed on ice and shipped overnight to our laboratory. Once in the laboratory, samples were aliquoted and preserved at $-80{ }^{\circ} \mathrm{C}$ until use.

\subsection{Enrichments}

Multiple strategies were tested in pilot studies to determine the best method for enrichment, and subsequent real-time PCR-based detection of $m c r-1 \mathrm{E}$. coli in feral swine feces. These enrichments utilized either Brain Heart Infusion (BHI) or EC broth (Becton Dickinson) with or without colistin and/or vancomycin (Millipore Sigma, Saint Louis, MO, U.S.) supplementation to allow for effective selection of the target bacteria. Briefly, $100 \mathrm{mg}$ aliquots of swine feces diluted 1:10 $(w / v)$ in phosphate buffered saline (PBS) were inoculated with one of five $\mathrm{mcr}-1$ E. coli strains at concentrations ranging between $10^{\circ}$ and $10^{4} \mathrm{CFU} / \mathrm{g}$. An aliquot of PBS was used to spike negative controls. Following inoculation, $9 \mathrm{~mL}$ of either BHI or EC broth, or broths supplemented with $1 \mu \mathrm{g} /$ $\mathrm{mL}$ colistin and/or $8 \mu \mathrm{g} / \mathrm{mL}$ vancomycin were added to each sample and incubated for $18 \mathrm{~h}$ at $37{ }^{\circ} \mathrm{C}$. The outcome of $m c r-1$ detection was evaluated for each media formulation prior to conducting the validation study (see below).

\subsection{Real-time PCR assay for the detection of $m c r-1$}

To facilitate $m c r-1$ detection from selective enrichments by real-time PCR, $100 \mu \mathrm{L}$ aliquots of enrichments were heated to $100{ }^{\circ} \mathrm{C}$ for $10 \mathrm{~min}$. Unlysed cells and debris were removed from each sample by centrifugation at $20,000 \times g$ for $1 \mathrm{~min}$. The resulting supernatant was transferred to a clean $1.5 \mathrm{~mL}$ conical tube, and $1 \mu \mathrm{L}$ was used for realtime PCR analyses in accordance with the method described by Irrgang et al. using a CFX96 Touch Real-Time PCR Detection System (Bio-Rad, Hercules, CA, U.S.) (Irrgang et al., 2016). A relatively small volume of template was used to limit the amount of real-time PCR inhibitors expected across diverse samples. Amplification of $m c r-1$ was possible for all five $E$. coli strains used in this study. Samples were considered positive if the quantification cycle (Cq) of amplification was $\leq 40$.

\subsection{Method validation for the detection of mcr-1 E. coli in feral swine feces}

To validate the method for mcr-1 E. coli detection, aliquots of 100 unique feral swine fecal samples were inoculated with one of five genetically distinct strains of $m c r-1 \mathrm{E}$. coli at concentrations ranging between 0.13 and $2200 \mathrm{CFU} / \mathrm{g}$ and enriched using the optimized formulation of EC broth supplemented with $1 \mu \mathrm{g} / \mathrm{mL}$ of colistin and $8 \mu \mathrm{g} /$ $\mathrm{mL}$ of vancomycin $(n=1000)$. Real-time PCR of sample enrichments for $m c r-1$ detection was performed as described above. An uninoculated control was also screened for each feral swine fecal sample $(n=100)$.

\subsection{Statistical analyses}

Simple linear regression models were developed to evaluate whether Cqs varied as a function of 1) the colistin-resistant strain present in the samples and 2) the original inoculum concentration used to spike the sample. Two models were tested - one which included the actual concentration of the inoculum and one which included the $\log _{10}$ transformed concentration to account for the likelihood that the data were not normally distributed. The two versions of the model were compared to determine which fit the data better based on lower RSS (Residual Sum of Squares) and AIC (Akaike's Information Criterion) values (Burnham et al., 2002). The model based on the $\log _{10}$ of bacterial concentration (CFU) per gram was determined to be a better fit to the data as compared to the model using the concentration of the inoculum, and was used for the subsequent analyses. The data were subset to exclude the negative control data. Samples that did not amplify by real-time PCR were set to a Cq of 45 . The regression models we examined were $\mathrm{Cq} \sim$ Strain + gConc and $\mathrm{Cq} \sim$ Strain $+\log$ gConc, where $\mathrm{Cq}$ was the real-time PCR cycle when a sample amplified at or above a set threshold, Strain was the colistin-resistant isolate associated with a sample, gConc was the spiked concentration of the inoculum per gram, and $\log$ gConc was the $\log _{10}$ of the spiked concentration. All analyses were conducted using $\mathrm{R}$ version 3.4.3 (R Core Team, 2017).

\section{Results}

3.1. Validation of the method for detection of mcr-1 E. coli in feral swine feces

A series of small-scale studies were first performed to determine an effective strategy for enrichment of $m c r-1 E$. coli from feral swine feces. These experiments evaluated the effects of BHI or EC broth with or without colistin and/or vancomycin supplementation on real-time PCR detection of $m c r-1$ in spiked and enriched fecal homogenates. Two $E$. coli strains were used in these assessments because of their different genetic backgrounds, where $m c r-1$ was plasmid-encoded on E. coli $\mathrm{M}$ 175 and chromosomally-encoded on E. coli POR 1303 (Ahlstrom et al., 2019). EC broth supplemented with both colistin $(1 \mu \mathrm{g} / \mathrm{mL})$ and vancomycin $(8 \mu \mathrm{g} / \mathrm{mL})$ improved $m c r-1$ detection compared to the other media formulations tested (data not shown). Thus, EC broth 
supplemented with both colistin $(1 \mu \mathrm{g} / \mathrm{mL})$ and vancomycin $(8 \mu \mathrm{g} / \mathrm{mL})$ was selected as the enrichment media for the validation study. In these small-scale experiments, $m c r-1$ was reliably detected when the initial inoculum was $\geq 10^{2} \mathrm{CFU} / \mathrm{g}$ feces (data not shown). However, our previous data suggests that fecal shedding of these $\mathrm{mcr}-1 \mathrm{E}$. coli occurs at levels of $\leq 10^{2} \mathrm{CFU} / \mathrm{g}$ feces, supporting the need to validate upstream enrichment strategies (Franklin et al., 2020).

To validate the enrichment and PCR method, extensive biological replication was used to assess the ability of the method to facilitate the detection of $m c r-1$ associated with $E$. coli in feral swine feces. In total, 1000 fecal samples were inoculated with one of the five target bacteria at concentrations ranging between 0.1 and $9.99 \mathrm{CFU} / \mathrm{g}(n=340)$, $10-49.99 \mathrm{CFU} / \mathrm{g}(n=170), 50-99 \mathrm{CFU} / \mathrm{g}(n=255), 100-149 \mathrm{CFU} / \mathrm{g}$ $(n=60)$, and $200-2200 \mathrm{CFU} / \mathrm{g}(n=175)$. Each of the five $m c r-1 \mathrm{E}$. coli strains was represented 200 times in the dataset, with 25 biological replicates tested for each strain at eight different target inoculum concentrations, with a primary focus on samples with inoculum concentrations $\leq 10^{2} \mathrm{CFU} / \mathrm{g}$ feces. This allowed for the mcr-1 detection response to be assessed across a gradient of target concentrations relevant for surveillance and monitoring activities. At the above inoculum ranges, $m c r-1$ was detected in an average of $32 \%, 72 \%, 88 \%, 95 \%$, and $98 \%$ of the samples, respectively (Table 1 and Fig. 1). Negative controls for all samples $(n=100)$ were $m c r-1$ negative by real-time PCR.

\subsection{Evaluation of strain-specific differences in detection outcomes}

Five different $m c r-1$ strains were used in this study to provide a better approximation of the vast physiological diversity that exists within $E$. coli, and the corresponding differential survival and growth parameters which may impact enrichment-based detection (Ahlstrom et al., 2019; Rasko et al., 2008). Thus, analyses to compare strainspecific differences in real-time PCR-based detection using the new method were conducted. Based on analysis of variance, both the strain and the inoculation dose were highly significant $(p<.0001)$ indicating that Cqs varied by strains and by the inoculum concentration (Table 2). Parameter estimates for the different strains (E. coli isolate SP 167 was randomly selected as the reference) demonstrated that the $\mathrm{Cq}$ of detection for each of the $E$. coli strains was significantly different from the reference strain. On average, E. coli strains M 175, POR 1303, and SP 278 were all detected at significantly lower Cqs compared with the reference strain, while strain SP 237 was detected on average at a significantly higher Cq compared to the reference strain.

\section{Table 1}

Real-time PCR-based detection of $m c r-1$ containing E. coli isolates spiked into fecal samples at different inocula concentrations.

\begin{tabular}{|c|c|c|c|c|c|}
\hline $\begin{array}{l}\text { Inoculum } \\
\text { dose (CFU) }\end{array}$ & Strain & $\begin{array}{l}\text { Total \# } \\
\text { samples }\end{array}$ & $\begin{array}{l}\text { \# real-time } \\
\text { PCR } \\
\text { positive }\end{array}$ & $\begin{array}{l}\text { \# real-time } \\
\text { PCR } \\
\text { negative }\end{array}$ & $\%$ detected \\
\hline \multirow[t]{5}{*}{0 to 9.99} & M 175 & 75 & 39 & 36 & 52 \\
\hline & Por 1303 & 40 & 21 & 19 & 52.5 \\
\hline & SP 167 & 100 & 5 & 95 & 5 \\
\hline & SP 237 & 75 & 26 & 49 & 34.67 \\
\hline & SP 278 & 75 & 37 & 38 & 49.33 \\
\hline \multirow[t]{5}{*}{10 to 49.99} & M 175 & 15 & 9 & 6 & 60 \\
\hline & Por 1303 & 75 & 57 & 18 & 76 \\
\hline & SP 167 & 25 & 19 & 6 & 76 \\
\hline & SP 237 & 15 & 5 & 10 & 33.33 \\
\hline & SP 278 & 15 & 15 & 0 & 100 \\
\hline \multirow[t]{3}{*}{50 to 99} & M 175 & 85 & 75 & 10 & 88.24 \\
\hline & SP 237 & 85 & 69 & 16 & 81.18 \\
\hline & SP 278 & 85 & 80 & 5 & 94.1 \\
\hline 100 to 149 & Por 1303 & 60 & 57 & 3 & 95 \\
\hline \multirow[t]{5}{*}{200 to 2200} & M 175 & 25 & 25 & 0 & 100 \\
\hline & Por 1303 & 25 & 25 & 0 & 100 \\
\hline & SP 167 & 75 & 72 & 3 & 96 \\
\hline & SP 237 & 25 & 24 & 1 & 96 \\
\hline & SP 278 & 25 & 25 & 0 & 100 \\
\hline
\end{tabular}

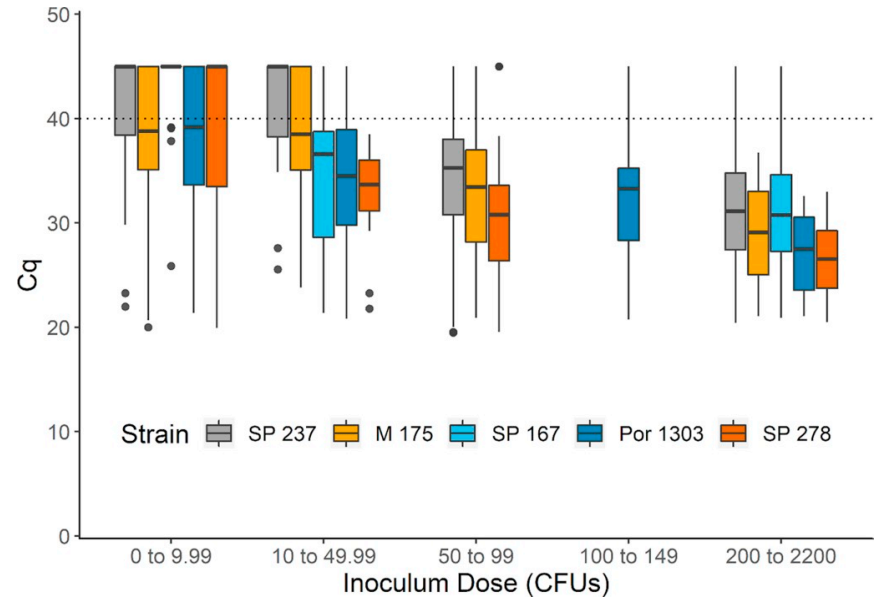

Fig. 1. Boxplot of Cq (quantification cycle) values obtained by real-time PCR for each of the enrichments for five $m c r-1$ positive $E$. coli strains within each of the five inocula dosage groups. Bars represent the median Cq across each strain within a group, the box represents the spread of the data within the 25th and 75th percentiles (first and third quartiles), the whiskers show $1.5 *$ Interquartile Range, and the black dots represent outliers. The dashed line is the threshold we defined for a positive sample ( $\mathrm{Cq} \leq 40$, negatives were set to a $\mathrm{Cq}=45)$.

Table 2

Linear regression model results evaluating the impact of strain and the log transformed inocula concentration on the real-time PCR Cq (quantification cycle) indicate that both strain and inocula concentrations affected Cqs.

\begin{tabular}{llllll}
\hline Variable & & $\begin{array}{l}\text { Parameter } \\
\text { estimate }\end{array}$ & $\begin{array}{l}\text { Standard } \\
\text { error }\end{array}$ & t value & $p$-value \\
\hline log Concentration & & 43.804 & 0.517 & 84.708 & $<0.001$ \\
Strain & M 175 & -1.349 & 0.645 & -2.093 & 0.037 \\
& Por 1303 & -1.956 & 0.650 & -3.010 & 0.003 \\
& SP 237 & 1.637 & 0.651 & 2.515 & 0.012 \\
& SP 278 & -2.864 & 0.646 & -4.431 & $<0.001$ \\
\hline
\end{tabular}

\section{Discussion}

The important contribution of $m c r-1$ in the transfer of polymyxin resistance is well-established, with its occurrence documented in over 40 countries since its discovery in 2015 (Liu et al., 2016; Sun et al., 2018). The emergence of $m c r-1$ in Enterobacteriaceae is linked to the use of colistin in animal agriculture as an in-feed growth promoter, and the low prevalence of colistin resistance recorded in the U.S. and Europe is likely due to neither region having approved colistin as an antibiotic for growth promotion (Irrgang et al., 2016; Meinersmann et al., 2017). This has prompted immediate measures to control the spread of resistance, including the ban of colistin for animal growth promotion in China since 2017 (Walsh and Wu, 2016). Interestingly, evidence has been mounting on wildlife's role in disseminating $\mathrm{mcr}-1$ mediated colistin resistance, as best exemplified by $\mathrm{mcr}$ detection within the microbiota of migratory birds in Asia, Europe, and South America, as well as in other wildlife species (Mohsin et al., 2016; Ruzauskas and Vaskeviciute, 2016). As colistin resistance has morphed into a global phenomenon, this has prompted the need for rapid diagnostic and characterization tools, including methods which can discern relevant differences in heteroresistant isolates (Caniaux et al., 2017; Falagas et al., 2008; Lo-Ten-Foe et al., 2007; Tan and Ng, 2007). Phenotypic methods (including susceptibility testing) have been widely utilized for this purpose, although it is recognized that some mcr-1containing isolates have colistin susceptibility that is less than the epidemiological breakpoint of $2 \mu \mathrm{g} / \mathrm{mL}$ (Chew et al., 2017). These issues have been summarized by a CLSI-EUCAST subcommittee with a warning regarding currently recognized poor performance of colistin 
susceptibility testing (EUCAST, 2016). Consequently, methods ranging from matrix-assisted laser desorption/ionization mass spectrometry (MALDI-TOF MS) to real-time PCR have been adopted for this purpose and applied to a variety of matrices (Bontron et al., 2016; Dona et al., 2017; Dortet et al., 2018; Li et al., 2017; Nijhuis et al., 2016).

In this study, a simple method was developed and validated for screening of mcr-1 E. coli in the feces of feral swine, a host which may be important for the maintenance and dissemination of this AMR determinant. The method involves a one-step selective enrichment procedure followed by detection of $m c r-1$ via real-time PCR. We optimized an enrichment strategy to improve the sensitivity of real-time PCR detection, with a combination of subinhibitory levels of colistin and vancomycin (Dona et al., 2017). These results compared equally or favorably to those using more complex methods to detect specific types of $E$. coli in feces (LeJeune et al., 2006). Matrix-specific validation for these diagnostic assays is highly recommended to account for the fitness and applicability of the method (Broeders et al., 2014). We determined that the utilization of the more selective enrichment protocol (supplemented EC broth) improved the sensitivity of the method, and this finding is corroborated by other studies (Chalmers et al., 2018).

Each of the wildlife-specific E. coli strains tested here belonged to a different multilocus sequence type, and $m c r-1$ was associated with at least three different genetic backgrounds (Ahlstrom et al., 2019). The MCR-1 gene in POR 1303 was chromosomally encoded, whereas SP 278, SP 237, and M 175 harbored $m c r-1$ in IncB/O/K/Z or IncHI2 plasmids. The genomic background of $m c r-1$ in SP 167 was unable to be determined. Therefore, physiological parameters such as plasmid copy numbers, differential growth rates, and differential nutrient requirements could have influenced detection outcomes. Nonetheless, the method was capable of detecting the five strains used here. Strainspecific differences in detection outcomes may have been observed; however, we cannot discount that this effect may be an artifact of the actual inoculum concentration used for each strain in each trial, particularly at the lower inoculum concentrations. For example, inocula of 0.1 CFU and 9.99 CFU were considered to be the same within the analyses conducted, although this difference likely has an important effect on detection outcomes. The applicability of this method to detect other $m c r$ variants and homologs requires additional investigation, but the selective pressures used for enrichment in this study are expected to be broadly applicable to other types of colistin-resistant $E$. coli. Therefore, we expect that additional real-time PCR assays designed to detect other $m c r$ variants and homologs can be used in conjunction with the enrichment strategy developed here with minimal optimization.

\section{Declaration of Competing Interest}

The authors declare that they have no known competing financial interests or personal relationships that could have appeared to influence the work reported in this paper.

\section{Acknowledgements}

This work was supported (in part) by the U.S. Department of Agriculture, APHIS. Feral swine fecal samples were provided by Steve Ditchkoff at Auburn University and by U.S. Department of Agriculture Wildlife Services specialists in Alabama. Field assistance was provided by Stephan Zenas and Matthew McDonough. We would like to thank Andy Reeves and John Pearce for critical review of this manuscript. Any use of trade, firm, or product names is for descriptive purposes only and does not imply endorsement by the U.S. Government.

\section{References}

Ahlstrom, C.A., Ramey, A.M., Woksepp, H., Bonnedahl, J., 2019. Early emergence of mcr1-positive Enterobacteriaceae in gulls from Spain and Portugal. Environ. Microbiol. Rep. 11 (5), 669-671. https://doi.org/10.1111/1758-2229.12779. Epub 2019 Jul 10.
Alba, P., Leekitcharoenphon, P., Franco, A., Feltrin, F., Ianzano, A., Caprioli, A., Stravino, F., Hendriksen, R.S., Bortolaia, V., Battisti, A., 2018. Molecular epidemiology of $\mathrm{mcr}$ encoded colistin resistance in enterobacteriaceae from food-producing animals in Italy revealed through the EU harmonized antimicrobial resistance monitoring. Front. Microbiol. 9, 1217.

Apostolakos, I., Piccirillo, A., 2018. A review on the current situation and challenges of colistin resistance in poultry production. Avian Pathol. 47, 546-558.

Bachiri, T., Lalaoui, R., Bakour, S., Allouache, M., Belkebla, N., Rolain, J.M., Touati, A., 2018. First report of the plasmid-mediated colistin resistance gene $\mathrm{mcr}-1$ in Escherichia coli ST405 isolated from wildlife in Bejaia, Algeria. Microb. Drug Resist. 24, 890-895.

Bevins, S.N., Pedersen, K., Lutman, M.W., Gidlewski, T., Deliberto, T.J., 2014. Consequences associated with the recent range expansion of nonnative feral swine. BioScience. 64, 291-299.

Biswas, S., Brunel, J.M., Dubus, J.C., Reynaud-Gaubert, M., Rolain, J.M., 2012. Colistin: an update on the antibiotic of the 21st century. Expert Rev. Anti-Infect. Ther. 10, 917-934.

Bontron, S., Poirel, L., Nordmann, P., 2016. Real-time PCR for detection of plasmidmediated polymyxin resistance ( $m c r-1)$ from cultured bacteria and stools. J. Antimicrob. Chemother. 71, 2318-2320.

Broeders, S., Huber, I., Grohmann, L., Berben, G., Taverniers, I., Mazzara, M., Roosens, N., Morisset, D., 2014. Guidelines for validation of qualitative real-time PCR methods. Trends Food Sci. Technol. 37, 115-126.

Burnham, K.P., Anderson, D.R., Burnham, K.P., 2002. Model Selection and Multimodel Inference: A Practical Information-Theoretic Approach. Springer, New York.

Caniaux, I., van Belkum, A., Zambardi, G., Poirel, L., Gros, M.F., 2017. MCR: modern colistin resistance. Eur. J. Clin. Microbiol. 36, 415-420.

Carroll, L.M., Gaballa, A., Guldimann, C., Sullivan, G., Henderson, L.O., Wiedmann, M., 2019. Identification of novel mobilized colistin resistance gene mcr-9 in a multidrugresistant, colistin-susceptible Salmonella enterica serotype Typhimurium isolate. MBio. 10.

Chalmers, G., Davis, K.E., Poljak, Z., Friendship, R., Mulvey, M.R., Deckert, A.E., ReidSmith, R.J., Boerlin, P., 2018. A method to detect Escherichia coli carrying the colistinresistance genes $m c r-1$ and $m c r-2$ using a single real-time polymerase chain reaction and its application to chicken cecal and porcine fecal samples. Can. J. Vet. Res. 82, 312-315.

Chew, K.L., La, M.V., Lin, R.T.P., Teo, J.W.P., 2017. Colistin and polymyxin B susceptibility testing for carbapenem-resistant and $m c r$-positive Enterobacteriaceae: comparison of Sensititre, MicroScan, Vitek 2, and Etest with broth microdilution. J. Clin. Microbiol. 55, 2609-2616.

Clemente, L., Manageiro, V., Correia, I., Amaro, A., Albuquerque, T., Themudo, P., Ferreira, E., Canica, M., 2019. Revealing mcr-1-positive ESBL-producing Escherichia coli strains among Enterobacteriaceae from food-producing animals (bovine, swine and poultry) and meat (bovine and swine), Portugal, 2010-2015. Int. J. Food Microbiol. 296, 37-42.

Dona, V., Bernasconi, O.J., Kasraian, S., Tinguely, R., Endimiani, A., 2017. A SYBR ${ }^{\circledast}$ green-based real-time PCR method for improved detection of mcr-1-mediated colistin resistance in human stool samples. J. Glob. Antimicrob. Resist. 9, 57-60.

Dortet, L., Bonnin, R.A., Pennisi, I., Gauthier, L., Jousset, A.B., Dabos, L., Furniss, R.C.D., Mavridou, D.A.I., Bogaerts, P., Glupczynski, Y., Potron, A., Plesiat, P., Beyrouthy, R., Robin, F., Bonnet, R., Naas, T., Filloux, A., Larrouy-Maumus, G., 2018. Rapid detection and discrimination of chromosome-and MCR-plasmid-mediated resistance to polymyxins by MALDI-TOF MS in Escherichia coli: the MALDIxin test. J. Antimicrob. Chemother. 73, 3359-3367.

European Committee on Antimicrobial Susceptibility Testing (EUCAST), 2016. Recommendations for MIC Determination of Colistin (polymyxin E) as Recommended by the Joint CLSI-EUCAST Polymyxin Breakpoints Working Group.

Falagas, M.E., Makris, G.C., Dimopoulos, G., Matthaiou, D.K., 2008. Heteroresistance: a concern of increasing clinical significance? Clin. Microbiol. Infect. 14, 101-104.

Fernandes, M.R., Sellera, F.P., Esposito, F., Sabino, C.P., Cerdeira, L., Lincopan, N., 2017. Colistin-resistant $m c r-1$-positive Escherichia coli on public beaches, an infectious threat emerging in recreational waters. Antimicrob. Agents Chemother. 61.

Franklin, A.B., Ramey, A.M., Bentler, K.T., Barrett, N.L., McCurdy, L.M., Ahlstrom, C.A., Bonnedahl, J., Shriner, S.A., Chandler, J.C., 2020. Gulls as sources of environmental contamination by colistin-resistant bacteria. Sci. Rep. 10, 4408.

Greig, J., Rajic, A., Young, I., Mascarenhas, M., Waddell, L., LeJeune, J., 2015. A scoping review of the role of wildlife in the transmission of bacterial pathogens and antimicrobial resistance to the food chain. Zoonoses Public Health 62, 269-284.

Irrgang, A., Roschanski, N., Tenhagen, B.A., Grobbel, M., Skladnikiewicz-Ziemer, T. Thomas, K., Roesler, U., Kasbohrer, A., 2016. Prevalence of $m c r-1$ in E. coli from livestock and food in Germany, 2010-2015. PLoS ONE 11, e0159863.

LeJeune, J.T., Hancock, D.D., Besser, T.E., 2006. Sensitivity of Escherichia coli O157 detection in bovine feces assessed by broth enrichment followed by immunomagnetic separation and direct plating methodologies. J. Clin. Microbiol. 44, 872-875.

Li, J.Y., Shi, X.M., Yin, W.J., Wang, Y., Shen, Z.Q., Ding, S.Y., Wang, S.L., 2017. A multiplex SYBR green real-time PCR assay for the detection of three colistin resistance genes from cultured bacteria, feces, and environment samples. Front. Microbiol. 8.

Liakopoulos, A., Mevius, D.J., Olsen, B., Bonnedahl, J., 2016. The colistin resistance $m c r-1$ gene is going wild. J. Antimicrob. Chemother. 71, 2335-2336.

Lim, L.M., Ly, N., Anderson, D., Yang, J.C., Macander, L., Jarkowski 3rd, A., Forrest, A., Bulitta, J.B., Tsuji, B.T., 2010. Resurgence of colistin: a review of resistance, toxicity, pharmacodynamics, and dosing. Pharmacotherapy. 30, 1279-1291.

Liu, Y.Y., Wang, Y., Walsh, T.R., Yi, L.X., Zhang, R., Spencer, J., Doi, Y., Tian, G., Dong, B., Huang, X., Yu, L.F., Gu, D., Ren, H., Chen, X., Lv, L., He, D., Zhou, H., Liang, Z., Liu, J.H., Shen, J., 2016. Emergence of plasmid-mediated colistin resistance mechanism MCR-1 in animals and human beings in China: a microbiological and molecular 
biological study. Lancet Infect. Dis. 16, 161-168.

Lo-Ten-Foe, J.R., de Smet, A.M.G.A., Diederen, B.M.W., Kluytmans, J.A.J.W., van Keulen, P.H.J., 2007. Comparative evaluation of the VITEK 2, disk diffusion, etest, broth microdilution, and agar dilution susceptibility testing methods for colistin in clinical isolates, including heteroresistant Enterobacter cloacae and Acinetobacter baumannii strains. Antimicrob. Agents Ch. 51, 3726-3730.

Meinersmann, R.J., Ladely, S.R., Plumblee, J.R., Cook, K.L., Thacker, E., 2017. Prevalence of $m c r-1$ in the cecal contents of food animals in the United States. Antimicrob. Agents Chemother. 61.

Mohsin, M., Raza, S., Roschanski, N., Schaufler, K., Guenther, S., 2016. First description of plasmid-mediated colistin-resistant extended-spectrum beta-lactamase-producing Escherichia coli in a wild migratory bird from Asia. Int. J. Antimicrob. Agents 48, 463-464.

Mourand, G., Jouy, E., Chauvin, C., Le Devendec, L., Paboeuf, F., Kempf, I., 2018. Dissemination of the $m c r-1$ colistin resistance gene among pigs: an experimental study. Vet. Microbiol. 221, 122-128.

Nijhuis, R.H.T., Veldman, K.T., Schelfaut, J., Van Essen-Zandbergen, A., Wessels, E., Claas, E.C.J., Gooskens, J., 2016. Detection of the plasmid-mediated colistin-resistance gene $m c r-1$ in clinical isolates and stool specimens obtained from hospitalized patients using a newly developed real-time PCR assay. J. Antimicrob. Chemother. 71, 2344-2346.

Osei Sekyere, J., 2019. Mcr colistin resistance gene: a systematic review of current diagnostics and detection methods. Microbiologyopen. 8, e00682.

R Core Team, 2017. R: A language and environment for statistical computing. In: R Foundation for Statistical Computing, Vienna, Austria.

Radhouani, H., Silva, N., Poeta, P., Torres, C., Correia, S., Igrejas, G., 2014. Potential impact of antimicrobial resistance in wildlife, environment and human health. Front. Microbiol. 5, 23.

Rasko, D.A., Rosovitz, M.J., Myers, G.S., Mongodin, E.F., Fricke, W.F., Gajer, P., Crabtree, J., Sebaihia, M., Thomson, N.R., Chaudhuri, R., Henderson, I.R., Sperandio, V., Ravel, J., 2008. The pangenome structure of Escherichia coli: comparative genomic analysis of E. coli commensal and pathogenic isolates. J. Bacteriol. 190, 6881-6893.
Rhouma, M., Beaudry, F., Theriault, W., Letellier, A., 2016. Colistin in pig production: chemistry, mechanism of antibacterial action, microbial resistance emergence, and one health perspectives. Front. Microbiol. 7, 1789.

Ruzauskas, M., Vaskeviciute, L., 2016. Detection of the mcr-1 gene in Escherichia coli prevalent in the migratory bird species Larus argentatus. J. Antimicrob. Chemother. $71,2333-2334$.

Snow, N.P., Jarzyna, M.A., VerCauteren, K.C., 2017. Interpreting and predicting the spread of invasive wild pigs. J. Appl. Ecol. 54, 2022-2032.

Sun, J., Zhang, H., Liu, Y.H., Feng, Y., 2018. Towards understanding MCR-like colistin resistance. Trends Microbiol. 26, 794-808.

Tan, T.Y., Ng, S.Y., 2007. Comparison of Etest, Vitek and agar dilution for susceptibility testing of colistin. Clin. Microbiol. Infect. 13, 541-544.

Walsh, T.R., Wu, Y.N., 2016. China bans colistin as a feed additive for animals. Lancet Infectious Diseases 16, 1102-1103.

Wang, Y., Tian, G.B., Zhang, R., Shen, Y., Tyrrell, J.M., Huang, X., Zhou, H., Lei, L., Li, H.Y., Doi, Y., Fang, Y., Ren, H., Zhong, L.L., Shen, Z., Zeng, K.J., Wang, S., Liu, J.H., Wu, C., Walsh, T.R., Shen, J., 2017. Prevalence, risk factors, outcomes, and molecular epidemiology of $m c r-1$-positive Enterobacteriaceae in patients and healthy adults from China: an epidemiological and clinical study. Lancet Infect. Dis. 17, 390-399.

Wang, R., van Dorp, L., Shaw, L.P., Bradley, P., Wang, Q., Wang, X., Jin, L., Zhang, Q., Liu, Y., Rieux, A., Dorai-Schneiders, T., Weinert, L.A., Iqbal, Z., Didelot, X., Wang, H., Balloux, F., 2018. The global distribution and spread of the mobilized colistin resistance gene mcr-1. Nat. Commun. 9, 1179.

Watkins, R.R., Smith, T.C., Bonomo, R.A., 2016. On the path to untreatable infections: colistin use in agriculture and the end of 'last resort' antibiotics. Expert Rev. AntiInfect. Ther. 14, 785-788.

Xavier, B.B., Lammens, C., Ruhal, R., Kumar-Singh, S., Butaye, P., Goossens, H., MalhotraKumar, S., 2016. Identification of a novel plasmid-mediated colistin-resistance gene, mcr-2, in Escherichia coli, Belgium, June 2016. Eur. Surveill. 21.

Yang, F., Gu, Y., Zhou, J., Zhang, K., 2019. Swine waste: a reservoir of high-risk bla NDM and $m c r-1$. Sci. Total Environ. 683, 308-316. 